\title{
AÇÃO DA PRODUÇÃO TEXTUAL ESCRITA POR ALUNOS SURDOS: ALGUMAS CONSIDERAÇÕES ${ }^{1}$
}

\author{
Vanessa Oliveira Almeida - UEMA ${ }^{2}$ \\ Zenailde Rodrigues Costa - UEMA ${ }^{3}$
}

\section{RESUMO}

Muitas escolas inclusivas entendem o português como segunda língua (L2) para surdos, mas não sabem como fazer para ensiná-los a ler e escrever sem tomar como base a oralidade ou o princípio do som, como feito com crianças ouvintes.

Este artigo aborda as implicações do professor de Português aprender a língua brasileira de sinais (LIBRAS) para assim se comunicar com os alunos surdos visto que há muitos matriculados e frequentando a rede de ensino. A cerca disso o presente artigo tem como problema: como a ausência do conhecimento aprofundado de LIBRAS pode influenciar na avaliação realizada pelo professor de língua portuguesa na produção escrita em língua portuguesa de alunos surdos? Para análise da problemática trazida, objetivos foram traçados: analisar como ocorre o processo de avaliação realizado pelo professor de Português nas produções escrita pelo aluno surdo; apresentar ao professor de língua portuguesa a gramática e estrutura da LIBRAS e evidenciar as estruturas gramaticais da LIBRAS.

É importante mencionar que este trabalho se justifica pela importância de o professor de português conhecer a línguas de sinais em seus aspectos linguísticos e sociais para saber como avaliar produções escritas pelos alunos surdos. Esta pesquisa fornecerá conhecimentos sobre a LIBRAS aos professores de modo a auxiliá-los no processo de ensino-aprendizagem de alunos surdos.

Este trabalho é uma revisão bibliográfica de natureza aplicada, analítico-descritiva. A metodologia utilizada no estudo foi de abordagem dedutiva e com procedimentos monográficos. Para fundamentar este trabalho foi consultada a leis no 10.436 de 24 de abril de 2002 (Lei da LIBRAS), autoras das áreas de linguística e de abordagens social da LIBRAS como Ronice Quadros (2007), e Honora e Lopes (2009) dentre outros.

Palavras-chaves: Alunos Surdos. LIBRAS. Português. Produções Escritas. Avaliação.

\footnotetext{
${ }^{1}$ Trabalho apresentado no Congresso Brasileiro Ciência e Sociedade (CBCS 2019), promovido pelo Centro Universitário Santo Agostinho, de 03 a 05 de outubro de 2019, em Teresina-PI.

${ }^{2}$ Licenciada em Pedagogia pela Universidade Estadual do Maranhão - UEMA; Pós-graduanda do curso de especialização em Libras pela faculdade FAESPI.E-mail:vanny123olly@ gmail.com

${ }^{3}$ Licenciada em Pedagogia pela Universidade Estadual do Maranhão - UEMA; Pós-graduanda do curso de especialização em Libras pela faculdade FAESPI. E-mail:nahilde.amomissoes@gmail.com
} 


\section{CONQEESSOC CIENCIAESOCIEDADE

\section{INTRODUÇÃO}

Nos últimos anos o povo e a comunidade surda ganharam visibilidade não somente na mídia, mas também nas pautas políticas e sociais através, principalmente, da representatividade da Língua Brasileira de Sinais (LIBRAS) na expansão do interesse por parte das pessoas em aprenderem esta língua. A Língua Brasileira de Sinais é a língua da comunidade Surda, na qual foi reconhecida pela Lei no 10. 436 em 24 de abril de 2002, e regulamentada pelo Decreto no 5.626 em dezembro de 2005.

Destacamos a complexidade deste tema, contextualizando o momento histórico em que ele se manifesta, nos quais pessoas surdas e seus familiares, vinculados a movimentos politicamente organizados, lutam pela afirmação de direitos sociais que thes foram negados ao longo dos séculos.

A presente pesquisa tem como foco as implicações que o professor de Português tem para assim se comunicar com os alunos surdos visto que há muitos matriculados e frequentando a rede de ensino. A cerca disso o presente artigo tem por problemática: como a ausência do conhecimento aprofundado de LIBRAS pode influenciar na avaliação realizada pelo professor de língua portuguesa na produção escrita em língua portuguesa pelos alunos surdos? Para análise dos dados foram traçados alguns objetivos: analisar como ocorre o processo de avaliação realizado pelo professor de Português nas produções escrita pelo aluno surdo; apresentar ao professor de língua portuguesa a gramática e estrutura da LIBRAS.

Sabemos que a Língua Brasileira de Sinas (LIBRAS), teve seu reconhecimento, no ano 2002 com a lei no 10.436 de 24 de abril, que a LIBRAS é "um sistema linguístico de natureza visual-motora, com estrutura gramatical própria" e "oriunda de comunidades de pessoas surdas do Brasil" (BRASIL, 2002). Por esta razão, a libras tem ganhando espaço na nossa sociedade e por ter muitos alunos surdos nas escolas municipais (visando assim a inclusão desses alunos nessas escolas), surgiu o questionamento sobre como os professores da disciplina de português avaliam as produções escritas dos alunos surdos vez que estes, em sua maioria, não costumam ter 


\section{CONGEFSSOCIENCIAESOCIEDADE \\ Inovação, Diversidaale e Sustentahililitade}

fluência nessa língua, vez que se comunicam em LIBRAS (sendo esta sua L1 e português sua L2).

A LIBRAS tem ganhando espaço na nossa sociedade e por ter muitos alunos surdos nas escolas municipais (visando assim a inclusão desses alunos nessas escolas), surgiu o questionamento sobre como os professores da disciplina de português avaliam as produções escritas dos alunos surdos, uma que vez que estes, em sua maioria, não costumam ter fluência nessa língua.

Este trabalho é uma revisão bibliográfica de natureza aplicada, analíticodescritiva. A metodologia utilizada no estudo foi de abordagem dedutiva e com procedimentos monográficos. Para fundamentar este trabalho foi consultada as leis $\mathrm{n}$ 은 10.436 de 24 de abril de 2002, autoras da área de linguística e abordagem social da LIBRAS como Ronice Quadros (2007) e Honora e Lopes (2009) dentre outros.

Segundo Goldfeld (2002) a língua de sinais surgiu com Ponce de Leon, quando ensinou quatro surdos, filhos de nobres por volta de 1520-1584. Ele desenvolveu uma metodologia de ensino para os seus alunos surdos onde inseriu a datilologia (que é a representação do alfabeto manual) e criou uma escola para professores surdos.

Depois que Ponce de Leon desenvolveu essa metodologia, começou a publicar livros relacionados à língua de sinais. Conforme Goldfeld (2002):

Em 1644 foi publicado o primeiro livro em inglês sobre língua de sinais chirologia, de J. Bulwer, que acreditava ser a língua de sinais universal e seus elementos constitutivos icônicos. O mesmo autor publicou em 1648 o livro Philocopus, nele afirma ser a língua de sinais capaz de expressar mesmos conceitos que a língua oral. (GOLDFELD, 2002, p. 28)

Segundo Diniz (2010) em 1760, na França, o Abade L'Epée começou o trabalho de instrução formal com duas surdas a partir da Língua de Sinais que se falava pelas ruas de Paris (datilologia/alfabeto manual e sinais criados) e gerou resultados positivos, pois a partir dessa época a metodologia que ele desenvolveu tornou-se conhecida e respeitada, e passou a ser utilizada pelo Instituto de Surdos e Mudos, em 


\section{CONBGESSEO CIENCIA:SOCIEDADE}

Paris. Depois das publicações de livros falando a respeitos da língua de sinais, foram surgindo novos estudos.

No ano de 1750 Abade L'Epée se aproxima de surdos que viviam pelas ruas de Paris, e com eles aprendeu a língua de sinais de maneira diferenciada, e a partir daí elaborou os "Sinais Metódicos", que consistia na sinalização utilizando a língua de sinais francesa, mas regida pelas normas gramaticais da língua francesa oral. Goldfeld (2002) afirma que "Abade teve um imenso sucesso na educação de surdos e transformou sua casa em escola pública, em poucos anos (1771 a 1785), sua escola passou atender 75 alunos, número bastante elevado para época". As línguas de sinais segundo Quadros (2004) são, portanto, consideradas pelos linguísticos como línguas naturais ou como um sistema linguístico e não como um problema patológico.

No Brasil a língua de sinais teve início no período da monarquia de D. Pedro II, começou o atendimento escolar especial às pessoas deficientes no início da década de 50 do século XIX. Foi criada a primeira escola para surdos pela lei $n=839$, de 26 de setembro de 1857, pelo imperador Dom Pedro II na cidade do Rio de Janeiro, sendo esta chamada de Imperial Instituto dos Surdos-Mudos (IISM) e permanece esse instituto até hoje com outro nome: Instituto Nacional de Educação de Surdos (INES). Nesse mesmo ano que foi criado a instituição para surdos se comemora o dia do surdo no Brasil.

Como vemos a educação de surdo com a comunicação em línguas de sinais no Brasil, começou um pouco tarde, mas ao ganhar mais espaço, instituições para surdos foram criadas. Com surdos passando a terem mais contato com a língua de sinais e uma instituição especializada para sua educação, surgiu a Língua Brasileira de Sinais (LIBRAS), que é a mistura da Língua de Sinais Francesa com os sistemas de comunicação já usados pelos surdos das mais diversas localidades do território nacional.

As línguas de Sinais não são universais, cada país tem a sua, por tanto, todos os países possuem sua respectiva língua de sinais. No Brasil a língua de sinais é chamada de LIBRAS, em Portugal de LGP (Língua Gestual Portuguesa) e nos Estados Unidos de ASL (American Sign Language). Assim já dito por Gesser (1971, p. 11) que “a língua de 


\section{conghESSOCIENCIAESOCIEDADE

sinais não é universal, dado que não funciona como "decalque" ou "rótulo" que possa ser colocado e utilizado por todos os surdos de todas as sociedades de maneira uniforme e sem influência de uso".

Por tanto todos os países possuem sua própria língua de sinais. Há várias línguas de sinais pelo mundo, que possui sua própria estrutura e seus próprios sinais e gramática.

Na seção seguinte passaremos a conhecer um pouco da história da língua brasileira de sinais e a sua lei. Para Azeredo (2006):

A Língua Brasileira de Sinais é um sistema linguístico legítimo e natural, utilizado pela comunidade surda brasileira, de modalidade gestual-visual e com estrutura gramatical independente da Língua portuguesa falada no Brasil. A LIBRAS, Língua Brasileira de Sinais, possibilita o desenvolvimento linguístico, social e intelectual daquele que a utiliza enquanto instrumento comunicativo, favorecendo seu acesso ao conhecimento cultural-científico, bem como a integração no grupo social ao qual pertence. (AZEREDO, 2006, p. 9)

Foi uma grande conquista da comunidade surda ter a sua própria língua para poder se comunicar, possibilitando o seu desenvolvimento linguístico, social e intelectual, favorecendo o seu conhecimento cultural bem como tendo a língua como artefato não somente cultural, mais identitário, uma vez que se projetam no mundo e o entendem, através da sua língua. O surdo passou a ter sentimento de pertencimento à sua comunidade e cultura própria.

A cultura surda é o jeito em que o surdo vê e entende o mundo, e isto resulta de toda experiência que ele vive no presente, mas considerando toda sua ancestralidade; é o jeito que surdo entende as coisas e modifica-as para torná-las acessíveis ao adequá-las às suas percepções visuais, que vai contribuir para a definição das suas identidades surdas. A pesquisadora surda Perlin descreve como essas identidades são formadas:

[...] as identidades surdas são construídas dentro das representações possíveis da cultura surda, elas moldam-se de acordo com a maior ou menor receptividade cultural assumida pelo sujeito. E dentro dessa receptividade cultural, também surge aquela luta política ou consciência opcional pela qual o 


\section{cowegESSOCIENCIASSOCIEDADE \\ -}

indivíduo representa a si mesmo, se defende da homogeneização, dos aspectos que o tornam corpo menos habitável, da sensação de invalidez, de inclusão entre os deficientes, de menos valia social. (PERLIN, 2004, p. 77- 78)

Como vimos, às identidades são formadas dentro das possíveis representações da cultura surda, e essas identidades podem ser: identidade cultural ou social e está em proximidade com outro que tem necessidade igual. Uma coisa importante é que para formar a identidade surda, é de fundamental importância que haja o contato entre eles. Existem identidades surdas hibridas (aqueles que nasceram ouvintes), identidades surdas em transição (filhos de pais ouvintes), identidades surdas incompletas (os que vivem sob a ideologia do ouvintismo) que é onde tem se a ideia de ser o ouvinte superior ao surdo, da identidade ouvinte ser superior à identidade surda, e as identidades surdas flutuantes (que são conscientes ou não de serem surdos).

A língua está em constante evolução, é dinâmico, um produto social em permanente evolução, “(...) é intrinsecamente heterogênea, múltipla, variável, instável e está sempre em desconstrução e em reconstrução" (BAGNO, 2007, p.35, grifos do autor).

Depois de um número considerável de pesquisas acerca das línguas de sinais, foram comprovadas que contêm os mesmos princípios implícitos de construção que as linguais orais possuem, ou seja, no sentido que tem um léxico sendo um sistema de regras que regem o uso desses símbolos, não violando os princípios de coerência, pois apesar dos textos nesta língua, elaborados por surdos falantes de LIBRAS, podem até apresentar alguns problemas na forma, os surdos conseguem de sob maneira inteligível terem suas ideias dotadas de coerência.

Passamos agora para a estrutura gramatical da LIBRAS, assim como a língua portuguesa tem sua estrutura, a LIBRAS também possui, a morfologia, coesão, coerência e semântica. Assim como a língua portuguesa, a LIBRAS também tem estrutura e gramatica própria, sendo possível às analises nos níveis morfológico, coesivo. 


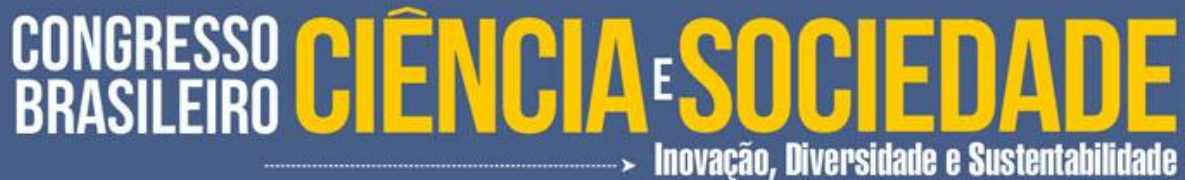

Como afirma Quadros, 2007 apud Kato (1988).

Assim como a gramática, convencional é entendida como conjuntos de regras necessárias que deve seguir na estruturação de textos, tais como: morfologia, sintaxe, coesão e coerência, acrescentando nesse repertoria a fonologia, a semântica e a pragmática, a gramatica da Libras, também, possui regras para a estruturação de textos, similares e contrativa com a gramática da língua Portuguesa, relacionados à morfologia, coesão, coerência e semântica. (QUADROS, 2007 APUD KATO e 1988).

A coerência que se tem nos textos do surdo não são iguais as da língua portuguesa, porém existe coerência no texto do surdo como nos afirma as pesquisas realizadas por Santos \& Ferreira- Brito (1995) elas revelam que textos nesta língua, apesar de apresentarem alguns problemas na forma, não têm violado o princípio de coerência: os surdos conseguem expressar de modo inteligível suas ideias. Por isso, verifica-se que a escrita de surdos, com domínio de LIBRAS, é dotada de coerência, embora nem sempre apresente certas características formais de coesão textual e de uso de morfemas gramaticais livres ou não.

O Professor de português deve avaliar as produções escritas dos alunos surdos tendo em vista a gramatica da LIBRAS, bem como a coerência e coesão seguida pelos mesmos, já que tendem escrever em português o que é sinalizado em Libras.

De acordo com Brito (1995), na Língua brasileira de sinais outra forma de produção é a topicalização ou tópico-comentário. A topicalização é feita no espaço com distribuição no espaço de frase, isto é, não seguindo necessariamente a ordem SVO, mas que não deixa de ter sentido e é muito utilizada pelos usuários da LIBRAS. Mas nem todas as possibilidades de organização sintática das frases são permitidas, vez que há casos em que o sentido é totalmente deturpado ou deixam as sentenças agramaticais, assim como nas línguas orais, demonstrando as propriedades sintáticas, semânticas e pragmáticas da LIBRAS, não sendo estas exclusivas das línguas orais como o português. 


\section{CONGEFSSOCIENCIAESOCIEDADE \\ -}

Ao olhar o texto do surdo, é possível um leigo falar que está tudo errado e que ele não sabe escrever, causando constrangimento aos surdos, conforme relata Honora e Lopes (2009):

O primeiro contato com o texto escrito por um surdo é para o ouvinte, desconcertante. Isso ocorre do fato de que o ouvinte desconhece a realidade do surdo, supõe que o escritor surdo tenha como Língua única e lou materna a língua portuguesa. Uma vez lembrado que a percepção é sensorial do surdo é essencialmente visual, tendo, por tanto, acesso restrito, ou nenhum acesso à modalidade oral do português, o ouvinte ainda se surpreende com o fato de que o surdo escolarizado demostre domínio tão restrito da língua Portuguesa. (HONORA, LOPES, 2009, p. 118)

O surdo deve ter acesso a sua língua materna, que é passada de pais para filho. Nem sempre a mãe do surdo tem deficiência auditiva. Devemos trabalhar com o conceito de L1 ( Língua materna é a Libras) e L2 ( Língua Portuguesa). A LIBRAS para que possa se comunicar sem problemas, e escrever conforme a sua língua permite, e o professor de língua portuguesa deve saber que a língua materna do surdo é a L1 e ele vai escrever de acordo com ela.

Para se avaliar com precisão a produção textual de um aluno surdo, é necessário que o professor de Língua Portuguesa tenha conhecimento da estrutura gramatical LIBRAS. Sabemos que não é uma tarefa fácil, mas é algo que se faz necessário. A avalição é um dos recursos que o professor utiliza para verificar o aprendizado dos seus alunos e quais são as suas dificuldades e as áreas que necessita ser trabalhado, acerca disso: Libâneo (1994, p. 195), afirma que a avaliação é:

Uma tarefa didática necessária e permanente do trabalho docente, que deve acompanhar passo a passo o processo de ensino e aprendizagem. Através dela, os resultados que vão sendo obtidos no decorrer do trabalho conjunto do professor e dos alunos são comparados com os objetivos propostos, a fim de constatar progressos e dificuldades e reorientar o trabalho para as correções necessárias. A avaliação é uma reflexão sobre o nível de qualidade do trabalho escolar tanto do professor como dos alunos (...) 


\section{congęSSOC CIENCIAESOCIEDADE

Os métodos de avaliação são bastante importantes no processo de ensino e aprendizagem, pois é um método continuo usado pelas escolas para que se possa refletir sobre o nível de desenvolvimento e também dos professores. Com os alunos surdos esses métodos não se divergem, porém faz-se necessário uma adaptação avaliativa por parte do professor de língua portuguesa.

Muitas vezes, o professor propõe ordens ou a resolução de problemas que não são compreendidos pelo aluno surdo que ignora ou não atinge os objetivos propostos pela tarefa, simplesmente por não entender o conteúdo da mensagem veiculada" (BOLSANELLO, 2005, p. 14)

O despreparo por parte dos professores e da equipe pedagógica é prejudicial ao desenvolvimento do aluno surdo, pois quando há um desconhecimento em relação à estrutura da LIBRAS resulta em avaliação prejudicial a escrita desse aluno. Ao avaliar a escrita de um aluno surdo não se deve levar em conta a forma como é escrita, porém o seu conteúdo e sua coerência. Deve - se considerar as dificuldades, pois a Língua Portuguesa é a segunda para aluno. O principal aspecto a ser considerado pelo professor é a sua originalidade e autoria das ideias.

A escola deve apresentar alternativas voltadas às necessidades linguísticas dos surdos, promovendo estratégias que permitam a incursão e o desenvolvimento da língua de sinais como primeira língua. Assim, as diferentes formas de proporcionar uma educação à criança de uma escola, dependem das decisões pedagógicas adotadas pela escola.

Ressaltando, a importância de desenvolver no aluno surdo a consciência da utilidade da escrita, oferecendo-Ihes uma metodologia de ensino própria. A pessoa deve ter contato com a língua portuguesa de forma funcional, a partir de objetos e coisas familiares para ela, estabelecendo a relação da palavra com as coisas. $\mathrm{O}$ uso de recursos visuais é fundamental para a compreensão da língua portuguesa, seguidos de uma exploração contextual do conteúdo em estudo.

Contudo, ainda existem muitas barreiras a serem ultrapassadas por esses profissionais da educação, como por exemplo a falta de preparo de certos educadores 


\section{CONGEFSSOCIENCIAESOCIEDADE

na maneira de lidar com a forma avaliativa desses alunos surdos. Por isso, a postura desses profissionais é um processo que exige uma auto avaliação e conscientização do trabalho que esta sendo oferecido a esses alunos surdos.

\section{CONSIDERAÇÕES FINAIS/CONCLUSÕES}

Nossa intenção, neste texto, foi a de oferecer conhecimento teórico mínimo para que o professor de língua portuguesa exercitasse a possibilidade de um olhar diferenciado diante de uma avaliação de produção textual escrita por alunos surdos, ciente das inúmeras dificuldades que acompanham seu aprendizado da língua portuguesa, desde o nascimento, em uma família geralmente de ouvintes.

Um sujeito extremamente ativo em seu processo de apropriação da escrita, construindo hipóteses e tentativas de dominar as regras do português. Um professor que reconhece esse esforço e tem conhecimento sobre as especificidades lingüísticas de um processo de aprendizagem de segunda língua, certamente lança mão de critérios diferenciados de avaliação. Adotar a avaliação diferenciada não significa relevar dificuldades dos alunos, com a crença de que suas aparentes limitações constituem desvios da "normalidade". As produções dos surdos não podem ser comparadas a de alunos falantes do português como língua materna, que ouvem e interagem por meio dele desde que nascem e, quando chegam à escola tem como objetivo conhecer uma das inúmeras variedades da língua: a norma padrão.

O parâmetro de comparação deve considerar as produções do próprio aluno surdo, nos diferentes estágios que percorre, apresentando características decorrentes da interferência da Libras e da sobreposição das regras da nova língua que está aprendendo. Como só podemos avaliar o que ensinamos, os critérios utilizados em cada avaliação devem ter alvos específicos. Por exemplo, se ensinamos regras de acentuação de paroxítonas, por meio de metodologias visuais que um aluno surdo possa compreender, nos textos que ele produziu, apenas esse será o objeto avaliado e não todos os aspectos gramaticais da língua que não poderiam ser dominados em um mês ou bimestre, sem a oportunidade de sistematização. 


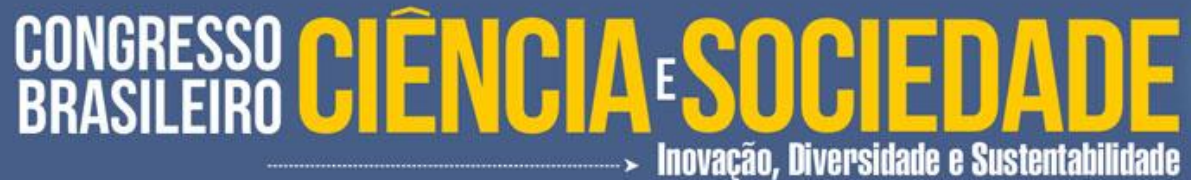

Obviamente, o conhecimento da língua de sinais por parte do professor de português contribuiria positivamente nesse processo. Mesmo que ele não possa ministrar aulas em Libras e português, o que é um processo linguístico inviável (ninguém pode falar duas línguas ao mesmo tempo), a fluência mínima permitiria a interação verbal significativa em sala de aula, oportunizando uma compreensão mais clara das muitas singularidades apresentadas pelos surdos na escrita. Segundo Lane (1992, p. 103), “a educação é o campo de batalha onde as minorias linguísticas ganham ou perdem seus direitos". Devemos estar atentos para que, muitas vezes, em nome da igualdade de oportunidades, em desigualdade de condições, não estejamos contribuindo para a destruição das diferenças de nossos alunos em sala de aula.

\section{REFERÊNCIAS}

AZEREDO, E. Língua Brasileira de Sinais: uma conquista histórica. Brasília: Ática, 2006.

BAGNO, M. Nada na língua é por acaso: por uma pedagogia da variação linguística. São Paulo: Parábola Editorial, 2007.

BRASIL. Lei n. 10.436, de 24 de abril de 2002. Dispõe sobre a Língua Brasileira de Sinais - Libras - e dá outras providências. Diário Oficial da República Federativa do Brasil, Brasília, 25 abr. 2002.

BOLSANELLO, Maria Augusta; ROSS, Paulo Ricardo [et all] Educação especial e avaliação de aprendizagem na escola regular: caderno 2 Universidade Federal do Paraná, Pró-Reitoria de Graduação e Ensino Profissionalizante, Centro Interdisciplinar de Formação Continuada de Professores; Ministério da Educação, Secretaria de Educação Básica- Curitiba: Ed. da UFPR, 2005.

GOLDFELD, Marcia, A Criança surda: Linguagem e cognição numa perspectiva sociointeracionista/ Marcia Golfeld.- 7ạ ed.- Plexus Editora, 2002. 


\section{CONGEESSOC CIENCIAESOCIEDADE \\ Inovação, Diversiliade e Sustentahilitiade}

HONORA, M.; FRIAZANCO, E.; LOPES, M. Livro ilustrativo da língua brasileira de sinais. São Paulo: Ciranda cultura, 2009.

LANE, Harlan. A máscara da benevolência: a comunidade surda amordaçada. Lisboa: Instituto Piaget, 1992.

LIBÂNEO, José Carlos. Didática. 2ª ed. São Paulo: Cortez, 1994.

QUADROS, Ronice Müller de \& PERLIN, Gladis. Estudos Surdos ed. Eletrônica, Ed. Arara Azul, 2007.

SANTOS, D. \& L. Ferreira-Brito (s/d) "Coesão e Coerência em Escrita. 1995 